\title{
Keine Entwarnung nach dem kalten Winter
}

Auch der relativ kalte Winter 2009/2010 hat wohl die Zeckenaktivität in FSME-Endemiegebieten nicht reduziert. Die Bayerische Gesellschaft für Immun-, Tropenmedizin und Impfwesen e. V. untersucht seit Jahren die Zusammenhänge zwischen Klima und Zeckenaktivität. Bisher zeichnet sich kein Muster ab.

Die Bayerische Gesellschaft befürchtet in diesem Jahr eine gewisse Impfmüdigkeit, wegen der Erfahrung mit der Schweinegrippeimpfung einerseits und weil große Teile der Bevölkerung nach dem kalten Winter an eine verringerte FSME-Gefährdung glauben. In Bayern sind nur ca. 30\% gegen FSME geimpft. In Österreich sind es $80 \%$. Obwohl dort das Risiko noch etwas höher ist als in Bayern, treten nur halb so viele FSME-Fälle auf.

FSME wird nicht nur durch Zeckenstiche übertragen. Auch über unbehandelte Milch von infizierten Tieren kann das Virus auf den Menschen übergehen. Dies war möglicherweise

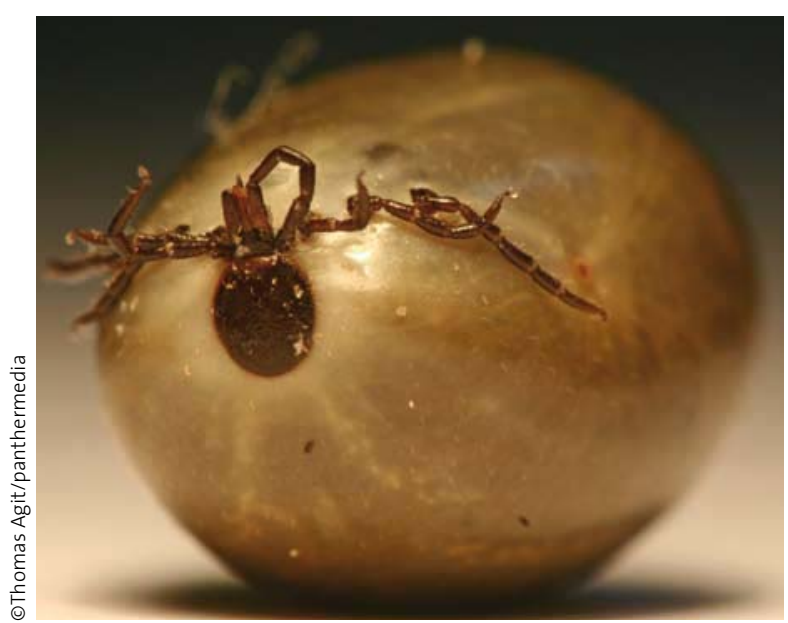

einmal sogar der wichtigere Infektionsweg. FSME hieß früher auch „undulierendes Milchfieber“. Auch wenn noch vereinzelte Fälle vorkommen, in denen Menschen durch kontaminierte Milch erkranken, spielt dieser Übertragungsweg heute epidemiologisch keine Rolle mehr.

Pressekonferenz der Bayerischen Gesellschaft für Immun-, Tropenmedizin und Impfwesen e. $V$, 5. Mai 2010

Diese Zecke hat ihr Opfer schon gefunden.

\section{PARTNERSCHAFTLICHES RISIKO}

\section{Vereint in der Demenz}

Ein Ehepartner, der an einer Demenz leidet, ist ein Risikofaktor für eine Demenzerkrankung. In einer Studie mit 1221 Ehepaaren erhöhte die Erkrankung eines Partners das Demenzrisiko für den anderen um den Faktor sechs. Das Risiko wird damit vergleichbar gesteigert wie durch die Genvariante APOE e4.

J Am Geriatr Soc 2010; online 5. Mai 2010

\section{COPD-EXAZERBATION}

\section{Vorsicht Infarktgefahr!}

COPD-Patienten haben grundsätzlich ein erhöhtes kardiovaskuläres Risiko. Besonders gefährdet sind sie in der Zeit nach einer akuten Exazerbation. In einer 2-JahresStudie mir 25857 Patienten war das Risiko für einen Herzinfarkt in den fünf Tagen nach der Exazerbation mehr als verdoppelt. Die Gefahr, einen Schlaganfall zu erleiden, lag in den Tagen 1-49 um 25\% höher. Chest 2010; 137:1091-97

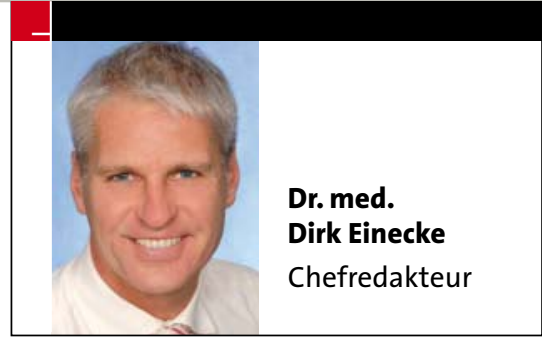

SCHON NACH EINER NACHT

\section{Schlafmangel macht süß}

Die Dauer des nächtlichen Schlafes hat erhebliche Auswirkungen auf den Glukosestoffwechsel: Schon nach einer Nacht mit wenig Schlaf nimmt die Insulinsensitivität ab. Das zeigt eine Studie mit neun gesunden Probanden, die nach vier und nach acht Stunden Schlaf untersucht worden waren. Ob umgekehrt durch ausreichend Schlaf die Glukosekontrolle bei Diabetikern optimiert werden kann, muss noch geprüft werden.

J Clin Endocrinol Metab 2010; online Mai 2010

\section{(Un-)Gewöhnliches aus Ihrer Praxis}

Ein Diabetespatient klagt nach der Therapieumstellung plötzlich über Durchfall - dabei ist die Ursache ganz und gar nicht iatrogen. Eine andere Patientin findet eine überraschende Begründung für ihre Herzgröße. Diese beiden Anekdoten aus ihrem Arztalltag erzählen Kollegen in diesem Heft auf S. 23. Hatten Sie in Ihrer Praxis auch Erlebnisse, die zum Schmunzeln oder Nachdenken anregen? Wollen Sie Ihre Geschichte mit unseren Lesern teilen? Dann schreiben Sie an: Brigitte.Moreano@springer.com. Jeder veröffentlichte Text wird honoriert. 